\title{
Reproductive Health Services in Owerri West Local Government Area, Imo State, Nigeria: Youths and Providers' Perspective
}

\author{
Ibebuike, J.E. ${ }^{1}$, Onyeneke, U.J. ${ }^{2}$, Chinedu-Eleonu, P. ${ }^{3}$, Korie, C.A. ${ }^{4}$, Njoku, G.C. ${ }^{5}$ \\ ${ }^{1}$ Department of Nursing Sciences, Imo State University, Owerri, Nigeria \\ ${ }^{2}$ Department of Public Health Nursing, Imo State College of Nursing Sciences, Orlu, Nigeria \\ ${ }^{3}$ Department of Public Health, Imo State University, Owerri, Nigeria \\ ${ }^{4}$ Department of Nursing, Imo State College of Nursing Sciences, Orlu, Nigeria \\ ${ }^{5}$ School of Midwifery, Awommama, Oru East, Imo State, Nigeria \\ Corresponding Author: Onyeneke, U.J.
}

\begin{abstract}
Reproductive health is central to human identity and imperative for health and well-being. This study was carried out in Owerri West Local Government Area of Imo State, Nigeria to investigate the perspective of youths and providers of reproductive health services toward its utilization and challenges. The study was a descriptive cross sectional study of which the multistage sampling technique was adopted to select samples for the study. A well-structured questionnaire was used to interview the subjects all of gave an informed consent to be part of the study. Results showed that the youth's view on impending factors of RHS include attitude of RHS workers, cost of provision of RHS, poor keeping of secret about one's health, lack of confidentiality among workers, parental influence, poor environment and poor road accessibility and lack of confidentiality. The providers generally identified the role RHS play in terms of family planning, antenatal care services, treatment of unsafe abortion, referral services, treatment and prevention of sexually transmitted infections, etc. They were of the view that some of the impediments affecting quality RHS in their communities were poor environment, lack of privacy, poor maintenance of the buildings for health care, fear of the elderly, poor attitude of some of the health workers, lack of accessible roads leading to health centers, poor availability of equipment and product supplies, treatment cost, etc. It was recommended that health awareness campaigns
\end{abstract}

concerning RHS and its associating risk factors should be made more pronounced in the society especially among youths.

Keywords: Reproductive Health Services, Sexual and Reproductive Health, Youths, Providers, Sexually Transmitted Infections

\section{INTRODUCTION}

Sexual and reproductive health (SRH) is a relatively new concept in the context of the dynamics of contemporary global issues. ${ }^{[1]}$ It came to the fore against the background of the worldwide increasing trend in the rates of liberal sexual behavior and activity, with its attendant reproductive health implications and sequelae. SRH is closely intertwined with the trio of Health, Population and environment, the three foremost challenging issues currently requiring global attention. It is greatly and significantly influenced by socio-cultural, political and religious considerations. Awareness about women's health issues that lead to the crystallization of this subject matter was raised by the passionate works of earlier leading advocates and champions of maternal wellness. Reproductive health services (RHS) is imperative for health and well-being. $\mathrm{Uka}^{[1]}$ stated that youth reproductive health is critical due to the gregarious sexual activities, which predispose them to negative sexual and 
reproductive health outcomes such as Sexually Transmitted Infections (STIs) including Human Immunodeficiency Virus (HIV), Acquired Immune Deficiency Syndrome (AIDS), unwanted pregnancies, unsafe abortion and death. Such negative sexual and reproductive health outcomes have economic, social, and health consequences that affect young people throughout their lives, as well as their families, countries, and the global community at large. ${ }^{[2]}$

The dilemma of youths has often been the issue of deficient knowledge to make informed decisions on reproductive health (RH) issues. Youth's lack of knowledge to the available RHS is one of the contributing variables that accelerate the susceptibility of youths to the trials or $\mathrm{RH}$ problems. Though sometimes the youths are aware of the penalties of indulging in risky sexual activities, they are however uninformed of their susceptibility and need to seek appropriate care ${ }^{[1]}$ According to a study by Geary et al. ${ }^{[3]}$ on the SRH perceptions and its barriers among school youths in selected districts of western Oromia, they stated that youths are constantly facing high risk and are suffering from various forms of SRH challenges. They are of the opinion that youth is commonly thought of as a period of optimum health. However, in sub-Saharan Africa, the prevalence of HIV, other sexually transmitted infections (STIs), among youths is high. It is therefore vital that they need to have clear and accurate understandings of what SRH means since such perceptions guide one's own sexual behavior and practices. Incidentally, it was noticed that most youths and parents did not have accurate understanding about SRH issues. In most cases, SRH was perceived as mere reproduction or giving birth to get children, getting married and abstaining from sex, protecting one-self from STI's among others. Conclusions were not reached as to the meanings of SRH. Hence, respondents were not cleared on the explanation given to SRH, suggesting the need for implementing culture-sensitive sexuality education for youths and for parents to improve their understanding about SRHS. ${ }^{[4]}$ Erumatha and Veronica ${ }^{[2]}$ opined that all clients of SRHS have the right to information about its benefits and availability of services, and to access these services regardless of their race, gender, sexual mutation, mental status, age; religion, political beliefs and ethnicity. In many places, adequate services that cater for the youths are not available.

Kerbo et al. ${ }^{[5]}$ illustrated that youths tend to be less informed, less experienced, and less comfortable in accessing reproductive health services than adults. They often lack basic reproductive health knowledge and access to affordable and confidential health services. That notwithstanding, majority of youths in their study had heard about youth friendly sexual and reproductive health services (YFSRHS). The most commonly mentioned sources of information about YFSRHS were from the mass media $270(73.6 \%)$ followed by from the health care professionals 167 (66.5\%). This finding is consistent with the finding of study ${ }^{[6]}$ where the major sources of information for reproductive health were radio $(80.4 \%)$, television $(73 \%)$ and school teachers $(71.8 \%)$ as responses of the respondents. Mbeba et al. ${ }^{[7]}$ stressed that in most developing countries, youths have inadequate access to appropriate SRH information contributing to unprotected sexual practices leading to unwanted pregnancy, HIV/ AIDS and STI's. Hence, there is a need for introducing $\mathrm{SRH}$ intervention focused on health education.

According to $\mathrm{Uka}^{[1]}$, parents have been known from various studies and from age immemorial to be the banquet of knowledge; however, when it comes to provision of $\mathrm{RH}$ issues, they become inadequate and seam to act and play ignorant in a bid of having the notion to protect the youth from what they perceive as being wrong and indiscipline. The Nigerian parent, hence often leave the youth in perpetual inexperience. Curiosity then leave 
the youth engaged in discussion with their fellow peers who might either not have adequate knowledge or provide incorrect and shoddy information. Sometimes they go on the internet to discover and read more and neither of them might be satisfactory. ${ }^{[8]}$ Mbeba et al. ${ }^{[7]}$ also postulated that youths face many significant SRHS challenges such as limited access to youth friendly service (YFS) including information on groups, sexuality and family planning, thus leading them to risky sexual behaviors resulting to high STI's. Even though sexual communication is a main means of conveying sexual values, expectations, beliefs, and knowledge between children and their parents, discussions on sex-related issues are forbidden in Africa and they believe that informing young ones about sex and teaching them how to protect themselves would lead them to sexual activity. To generate significant improvements in youths' use of health services, and in their sexual and reproductive health, the interventions will need to be scaled up and implemented over longer time frames. This will reinforce the need for evidence on the sustainability of youth-friendly health services interventions. ${ }^{[8]}$ This study was carried out to investigate the view of youths and providers to the provision and utilization of reproductive health services in rural communities of Owerri West Local Government Area, Imo State, Nigeria.

\section{MATERIALS AND METHODS}

The study was a descriptive cross sectional study carried out in rural communities of Owerri West Local Government Area of Imo State, Southeastern Nigeria. The multistage sampling technique was adopted to select samples for the study. A well-structured questionnaire was used to interview the subjects and obtain data for the study. All subjects used for this study gave an informed consent to be part of the study.

\section{RESULTS}

Table 1 showed information on the demographic characteristics of the subjects. The code ' $F Y$ ' was used for female youths; 'MY' was used for male youths; and ' $\mathrm{P}$ ' was used for providers of RHS. The table showed that all of the interviewers were Christians, and many had tertiary education.

Table 1: Demographic characteristics of the subjects

\begin{tabular}{|l|c|c|l|c|}
\hline Code & Sex & Age & Religion & Education \\
\hline FY1 & Female & 24 & Christianity & Tertiary \\
\hline FY2 & Female & 21 & Christianity & Tertiary \\
\hline FY3 & Female & 19 & Christianity & Tertiary \\
\hline FY4 & Female & 24 & Christianity & Secondary \\
\hline FY5 & Female & 16 & Christianity & Secondary \\
\hline MY1 & Male & 19 & Christianity & Tertiary \\
\hline MY2 & Male & 23 & Christianity & Tertiary \\
\hline MY3 & Male & 21 & Christianity & Tertiary \\
\hline MY4 & Male & 24 & Christianity & Tertiary \\
\hline MY5 & Male & 22 & Christianity & Tertiary \\
\hline P1 & Female & 35 & Christianity & BSCN \\
\hline P2 & Female & 33 & Christianity & RN, RM \\
\hline P3 & Female & 37 & Christianity & RN, RM \\
\hline P4 & Female & 33 & Christianity & RM \\
\hline P5 & Female & 30 & Christianity & Community Health \\
& & & & worker \\
\hline \multicolumn{7}{|l}{ FY: Female youth, MY: Male youth, P: Provider } \\
\hline
\end{tabular}

Table 2 showed the view of the youths and providers on RHS. The youth's knowledge on RHS could be described as fair knowledge. They generally agreed that RHS render services such as antenatal care (ANC), advice, family planning, test, treatment, etc. Some of their expressions on the meaning of RHS are as follows: "services rendered to youths to help them solve reproductive health problems" (FY1), "things to do to ensure that my reproductive system is in order, to make sure that I take care of my reproductive system like my personal hygiene and how I interact with the opposite sex"(FY2). Similarly, the MY2 described RHS as "how you can take care of yourself when it comes to trying to have a very good and sound reproductive system" and MY4 were about the same direction, describing RHS as "those things I can do to keep my reproductive system in sound shape"; "the little way I do take care of myself to provide my health needs to avoid start crying tomorrow" (MY3). MY5 also described RHS as "a process of managing the reproductive system of a male by taking care of a male reproductive organ". The 
youths' view on impending factors of RHS include attitude of RHS workers, cost of provision of RHS, poor keeping of secret about one's health, lack of confidentiality among workers, parental influence, poor environment and poor road accessibility and lack of confidentiality. According to MY5, "It baffles me when I see most of the health workers lacking confidentiality by disclosing patient's health to one another". The youths also recognized poor awareness and fear as some of the factors: "Lack of awareness may be a problem causing fear of going to the hospital "(FY1).For me it is "fear of those instruments, injections and the way nurses carry it, no privacy, and asking private questions in public" (FY4).The youths' view on enabling factors of RHS include more awareness creation, giving confidentiality and maintaining privacy, affordability of products, proper training of RHS providers, accessibility of roads to care centers, provision of good environment, provision of adequate equipment and products.
The providers generally identified the role RHS play in terms of family planning, antenatal care (ANC) services, treatment of unsafe abortion, referral services, treatment and prevention of sexually transmitted infections (STIs), etc. They were of the view that some ofthe impediments affecting quality RHS in their communities were poor environment, lack of privacy, poor maintenance of the buildings for health care, fear of the elderly, poor attitude of some of the health workers, lack of accessible roads leading to health centers, poor availability of equipment and product supplies, treatment cost, etc. Some of their responses were as follows: "The impediments are no enough space for privacy, inadequate skills and knowledge among health workers, bad attitude of some of the health workers and cost of treatment "(P2). "I think seeing an elderly in the hospital makes youths not to come. Government and the communities should make the health facilities bigger to allow for privacy" (P1).

Table 2: Thematic Area and outcome for Youths and Providers of RHS

\begin{tabular}{|c|c|}
\hline Thematic Area & Outcome \\
\hline Youth Knowledge of RHS & $\begin{array}{l}\text { - Fair knowledge } \\
\text { - The generally agreed that RHS render services such as ANC, advice, family planning, test, } \\
\text { treatment, etc. }\end{array}$ \\
\hline $\begin{array}{l}\text { Youth view on Impending factors of } \\
\text { RHS }\end{array}$ & $\begin{array}{ll}\text { - } & \text { attitude of RHS workers } \\
\text { - } & \text { cost of provision of RHS } \\
\text { - } & \text { poor keeping of secret about ones health } \\
\text { - } & \text { lack of confidentiality among workers } \\
\text { - } & \text { parental influence }\end{array}$ \\
\hline Youth view on enabling factors of RHS & $\begin{array}{ll}\text { - } & \text { creating awareness } \\
\text { - } & \text { confidentiality and maintaining privacy } \\
\text { - } & \text { proper training of RHS providers } \\
\text { - } & \text { accessibility of roads to care centers } \\
\text { - } & \text { provision of good environment } \\
\text { - } & \text { provision of adequate equipment and products } \\
\text { - } & \text { provision of adequate staff }\end{array}$ \\
\hline $\begin{array}{l}\text { Providers view on Impending factors of } \\
\text { RHS }\end{array}$ & $\begin{array}{l}\text { - } \\
\text { - } \quad \text { lack of privacy, } \\
\text { - } \quad \text { poor maintenance of the buildings for health care, } \\
\text { - } \quad \text { fear of the elderly, } \\
\text { - } \quad \text { lack of accessible roads leading to health centers, } \\
\text { - } \quad \text { poor availability of equipment and product supplies, } \\
\text { - treatment cost, etc. }\end{array}$ \\
\hline
\end{tabular}

\section{DISCUSSION}

In this study, the most common barriers to providing health services to youths, and to providing YFS specifically that were reported, relate to shortages of staff who had received training on the provision of youth-friendly health services and the lack of a dedicated space for youths at the facilities. In addition, lack of knowledge and skill of the providers to 
provide appropriate and age-specific reproductive health services, seeing RHS as inappropriate to youths, cultural beliefs of the providers (shameful and rude), the feeling that it may encourage youths for more sexual activities and moral reasons leading to disapproval and premarital sex (moral decadence) are also major factors hindering the provision of youth reproductive health services by the providers. This was corroborated in a study by Geary et al. ${ }^{[3]}$ Similarly, a study in Nigeria by Bukenya et al. ${ }^{[10]}$ in their survey on the perception and practices of private medical providers to adolescents, they highlighted that religious affiliation of the providers influenced their practices. In a qualitative study in Kenya ${ }^{[11]}$, service providers reported being undecided between cultural, religious values and beliefs in offering SRH services to youths. Other studies in Zambia ${ }^{[12]}$ and Kenya ${ }^{[13]}$ revealed that service providers who are married and had more education showed more youthfriendly attitudes and willingness in providing services. Also, in a quantitative study aimed at examining health care workers' toward SRH services to unmarried people in Ethiopia, lower education level, being a health extension worker, and lack of training on SRH services were found to be significantly associated with negative attitude towards their provision of SRH services. ${ }^{[5]}$ This is further affirmed a study in Nigeria that many service providers excluded youth and unmarried individuals from family planning services due to lack of basic skills and knowledge in family planning provisions. ${ }^{[15]}$

In addition, social factors affect service providers' decision in the delivery of sexual health as shown in this study. This was also revealed in a study in Turkey, which found that $87.3 \%$ of midwifery students in Turkey believed a girl should be a virgin when she is married, and 50.9\% believed abortion was morally wrong and $23.6 \%$ thought only married couples should be informed of contraceptive methods. ${ }^{[15]}$ Thus, showing that they are influenced by judgments and concluding that ethical dilemma, moral doubts and cultural factors influence the decision of professionals in delivering sexual health services. Spettel ${ }^{[16]}$ in their study on providers' bias in the provision of contraceptives to adolescent girls and young women in South West Nigeria asserted that youths who want contraceptives may encounter discouraging attitudes and practices from contraception providers, which may limit their ability or willingness to seek SRH care.

Furthermore, bias among providers can shape the patient-provider interaction. Provider bias was originally understood primarily in terms of bias against the use of specific contraceptive methods for different populations (e.g. unmarried or nulliparous women), largely based on erroneous medical rationales. In their own view, providers' bias may stem from factors beyond technical knowledge. However, in sub-Saharan Africa, provider's bias in youth's reproductive services has been shown in some contexts to stem providers' inadequate technical skills or lack of confidence in their skills. In addition, this bias may also result from their personal beliefs. It is also possible that beliefs may be related to the appropriateness of a certain method for a given population, such as perceiving intrauterine devices (IUDs) to be only proper for multiparous women, or the general provision of contraceptives for given population, such as believing that contraceptive use among unmarried women promotes promiscuity. These bias may lead to non-evidence based restrictions on youth's access to contraception, hence denying methods to youths based on their age, marital status or parity. ${ }^{[17]}$ According to Godia et al. ${ }^{[13]}$, Health Service providers (HSP) described their experiences as being either negative or positive. Negative experiences reflect barriers and challenges. These barriers could be further classified into three broad thematic areas: factors that were related to the HSP themselves, the young people and the service delivery 
processes. In a health service provider related barriers, limited knowledge and competency, HSP dilemmas, communication and language barriers, staff shortage, age of staff, poor staff motivation and selection criteria for HSP training barriers were commonly recognized and mentioned by the majority of HSP from all sites.

In this study, most people also expressed concerns about language and communication with the youths who often used native languages which HSPs do not comprehend. According to Godia et al. ${ }^{[13]}$, there are lack of essential equipment and supplies (medication, contraceptives), lack of anonymity and privacy and high workload were barriers mentioned by the majority of HSP in all types of facilities and long waiting times were mentioned by most providers from integrated facilities. In another study ${ }^{[18]}$ that sought to explore health service providers' (HSP) perceptions and experiences of providing sexual and reproductive health (SRH) services to young people in Kenya, three main thematic areas emerged: HSPs' understanding of youth friendly services (YFS), policies and guidelines, HSP training and provision of SRH services and HSP competency. In it, majority of HSP from health centers in Nairobi reported the presence of long queues at the health facilities. In addition, clients who needed in-depth discussion on particular issues were not well attended to as the contact time between HSP and youths was short. Bukenya et al. ${ }^{[10]}$ emphasized that irrespective of having received training in YFS provision, the majority of HSPs are reluctant to provide the full range of SRH services to youth. Although HSPs know that in principle they should not deny them any of the SRH services, their personal values and beliefs sometimes take precedence. This reluctance stems from HSP's cultural, religious beliefs as well as perceived medical eligibility. There seem to be a tension and contradiction between HSPs' cultural and traditional values, existing policies and youth rights to receive SRH services. Possibly, HSPs feel and behave more as parents when dealing with them and make their judgment from the perspective of their parental instincts and identity. Previous studies ${ }^{[16-18]}$ have also found out that HSPs' own cultural and religious values may hinder them from providing SRH services to young girls. A study [19] in Swaziland showed that culture, values and beliefs played a key role. For instance, emergency contraception was only provided to girls who had been raped and only if they were brought in by the police. HSPs difficulty in providing SRH services to youths could be presumed to originate from their inability to deal with them at a personal level. This could reflect their poor understanding of their psychology and recognized difficulty in providing counseling and interpersonal communication skills. This could also be reflective of deficiencies in the content of the existing SRH training curriculums. The providers views on impending factors of RHS include poor environment, lack of privacy, poor maintenance of the buildings for health care, fear of the elderly, poor attitude of some of the health workers, lack of accessible roads leading to health centers, poor availability of equipment and product supplies, treatment cost, etc. The study can be contrasted with the study by Geary et al. ${ }^{[3]}$ where the most common barriers to providing health services to youths, and to providing YFS specifically were reported to be shortages of staff who had received training on the provision of youth-friendly health services and the lack of a dedicated space for youths at the facilities.

\section{CONCLUSION}

In conclusion, the views of the youths on how to increase the use of reproductive health services include affordability of the services, making the environment 'spaced enough' for privacy, making the services more attractive and awareness creation. The providers views on impending factors of RHS include poor environment, lack of privacy, poor maintenance of the buildings for health care, 
fear of the elderly, poor attitude of some of the health workers, lack of accessible roads leading to health centers, poor availability of equipment and product supplies, treatment cost. It was recommended that health care providers should be trained on youth reproductive health services and that health awareness campaigns concerning RHS and its associating risk factors should be made more pronounced in the society especially among youths.

\section{Acknowledgement: None}

\section{Conflict of Interest: None}

\section{Source of Funding: None}

\section{Ethical Approval: Approved}

\section{REFERENCES}

1. Uka VK. Consumer's and provider's perspective regarding youth reproductive health services in Calabar South Local Government Area of Cross River State Nigeria (Unpublished). 2016.

2. Eremutha F, Veronica CG. Barriers Limiting Youth Access to Reproductive Health Services by Primary Health Care Facilities in Nigeria. Universal Journal of Public Health. 2019; 7(1): 36-43.

3. Geary KO, Gomez-Olive TM, Norris HU. Perception of Reproductive Health services among youths. Glob J Reprod Med. 2014; 2(7): 80-87

4. Birhanu Z, Kora T, Jabana GM. Sexual and Reproductive Health Services use, perceptions and barriers among young people in Southwest Oromia, Ethiopia. Ethipioian Journal of Health Sciences. 2017; 28(1): 37-48.

5. Kerbo AA, Tefera TB, Kuti KA, Nur RA. Youth Friendly Sexual and Reproductive Health Services Utilization and Associated Factors in Bale Zone of Ethopia: A Community Based Cross Sectorial Study. Journal Women's Health Reproductive Medicine. 2018; 2(1): 11.

6. Seth C, Appiah Y. Balancing Youth Friendliness of sexual and reproductive health service delivery and service utilization among Ghanaian youth.
International Nursing Review. 2014; 59(8): 78-83.

7. Mbeba PM, Nkuye MS, Magembe GE, Yothan WL, Mellan AO, Mkuwa SB. Barriers to sexual and reproductive health services and rights among young people in Mtwara district, Tazania: a qualitative study. The plan African Medical Journal. 2012; 13(1): 23-26.

8. Mngadi PT, Faxelid E, Zawane IT, RansjoArvidson AB. Health providers' perception of adolescent sexual and reproductive health care in Switzerland. International Nursing Review. 2018; 55(2): 111-118.

9. USAID. High Impact Practices: AdolescentFriendly Contraceptive Services: Mainstreaming Adolescent- Friendly Elements into Contraceptive Services. USAID. 2015.

10. Bukenya JN, Mulogo E, Kibira SP, Muhumuza C, Atuyambe L. Health Facilities' Readiness to Provide Friendly Reproductive Health Services to Young People Aged 10-24 years. Glob J Reprod Med. 2017; 2(3): 55-58.

11. Chandra-MouliV, McCarraher DR, Phyllips SJ, Williamson NE, Haimsworth G. Contraception for adolescents in low and middle income countries: needs, barriers, and access. Reprod Health. 2014; 11(1): 1117.

12. Gelo O, Braakmann D,BenektaTJ. Quantitative and Qualitative Research: Beyond the debate. Integrative Psychological and Behavioural Science. 2008; 42(3): 266-290.

13. Godia PM, Olenja JM, Lavussa JA, Quinney D, Hoffman JJ, Van Den B. Sexual Reproductive Health Service Provision to Young People in Kenya Health Service Providers Experiences. BMC Health Services Research. 2013; 13:476.

14. Ojong I, Akpan M, Alasia MO, Nlumanze F. A comparative study on reproductive health awareness among urban and rural secondary school students in Cross River State, Nigeria. Journal of Research in Nursing and Midwifery. 2014; 3(1).21-25.

15. Lambert VA, Lambert CE. Qualitative descriptive Research: An acceptable design. Pacific Rim International Journal of Nursing Research. 2012; 16(4): 225-256.

16. Spettel J. The Importance of reproductive Health. 2015; Available at: https://medicalservices.nph.org/2015/05/16/t 
Ibebuike, J.E et.al. Reproductive health services in Owerri West Local Government Area, Imo State, Nigeria: youths and providers' perspective

he-importance-of-reproductive-health [Retrieved July 16, 2020]

17. UNFPA. Adolescent Fact Sheet. The power of 1.8 Billion: Adolescents, Youth and the Transformstion of the future Youth in Subsaharan African: UNFPA. 2014.

18. Justine NB, Edgar M, Simon PSK, Christine M, Lynn MA. Health Facilities' Readiness to Provide Friendly Reproductive Health Services to Young People Aged 10-24 years. Glob J Reprod Med. 2017; 2(3): 8589.

19. Dawson K. The importance of sexual and reproductive health. 2014. Available at:
http://westernhealth.nl.ca/uploads/Your\%20 health\%20matters/feb-your-health-sexualand-Reproductive-health.pdf [Retrieved: May 3 2020].

How to cite this article: Ibebuike, J.E., Onyeneke, U.J., Chinedu-Eleonu, $\mathrm{P}$ et.al Reproductive health services in Owerri West Local Government Area, IMO State, Nigeria: youths and providers' perspective. International Journal of Science \& Healthcare Research. 2021; 6(3): 208 208-215. DOI: https://doi.org/ 10.52403/ijshr.20210736

$* * * * * *$ 